\title{
Mechanical and Dielectric Properties of a New Polymer Blend Composed of 1,2-Bis(vinylphenyl)ethane and Thermosetting Poly(phenylene ether) Copolymer Obtained from 2,6-Dimethylphenol and 2-Allyl-6-methylphenol
}

\author{
Jun Nunoshige, ${ }^{1,2, \dagger}$ Haruo AKahoshi, ${ }^{2}$ Yonggui Liao, ${ }^{3}$ Shin Horiuchi, ${ }^{3}$ \\ Yuji SHIBASAKI, ${ }^{4}$ and Mitsuru UEDA ${ }^{4}$ \\ ${ }^{1}$ Japan Chemical Innovation Institute, Tokyo Institute of Technology, \\ 2-12-1 O-okayama, Meguro-ku, Tokyo 152-8552, Japan \\ ${ }^{2}$ Hitachi Research Laboratory, Hitachi Ltd., 7-1-1 Omika, Hitachi 319-1292, Japan \\ ${ }^{3}$ Nanotechnology Research Institute, National Institute of Advanced Industrial Science and Technology (AIST), \\ 1-1-1 Higashi, Tsukuba 305-8565, Japan \\ ${ }^{4}$ Department of Organic and Polymeric Materials, Tokyo Institute of Technology, \\ 2-12-1 O-okayama, Meguro-ku, Tokyo 152-8552, Japan
}

(Received March 30, 2007; Accepted May 12, 2007; Published June 26, 2007)

\begin{abstract}
A novel low-dielectric-loss thermosetting material was developed by blending poly(2-allyl-6-methylphenol-co-2,6-dimethylphenol) (Allyl-PPE) with 1,2-bis(vinylphenyl)ethane (BVPE). BVPE could be used effectively as a crosslinking agent for Allyl-PPE, decreasing the cured temperature to $250^{\circ} \mathrm{C}$ or lower. The cured products exhibited better thermal and thermomechanical properties than those of non-functionalized-PPE/BVPE blends because of the homogeneity of the cured products. The phases-separated morphologies with small domain sizes less than $10 \mathrm{~nm}$ could be observed by employing energy-filtering transmission electron microscopy. The effect of the composition of the blends on the dielectric constant and the dielectric loss were also evaluated. [doi:10.1295/polymj.PJ2006280] KEY WORDS Insulating Material / Low Dielectric Loss / Poly(phenylene ether) / 1,2-Bis(vinylphenyl)ethane / Thermosetting Resin / Polymer Alloy /
\end{abstract}

In recent years, an operating frequency at $\mathrm{GHz}$ bands has been frequently used for the signals in communication equipments such as portable telephones, and the working frequency $(f)$ is believed to be much higher in the future due to the increasing demands for the communication with large amount of information. Dielectric loss is caused by the capacitive effect of the dielectric material, and it should be kept in low not to lose the electric current. A dielectric loss $(\alpha)$ of an insulating material is expressed with the dielectric constant $\left(\varepsilon^{\prime}\right)$ and the dielectric loss tangent $(\tan \delta)$ by the following equation (1).

$$
\alpha \propto \sqrt{\varepsilon^{\prime}} \cdot \tan \delta \cdot f
$$

To avoid large $\alpha$, it is necessary to develop a novel insulating material with a low $\varepsilon^{\prime}$ and $\tan \delta$. Many lowdielectric-constant polymers, such as polyimides, poly(aryl ether)s, poly(ether ketone)s, heteroaromatic polymers, fluoropolymers and so on, have been proposed as insulating materials. ${ }^{1-5}$ Among them, poly(2,6-dimethyl-1,4-phenylene ether) (PPE) is one of the best candidates because of its excellent dielectric properties, $\varepsilon^{\prime}$ of 2.5 and $\tan \delta$ of 0.002 (at $10 \mathrm{GHz}$ ). ${ }^{6}$ However, its glass transition temperature is around $210^{\circ} \mathrm{C}$, which is inadequate for a lead-free process.
To improve this property, we previously reported a synthesis of thermosetting PPE resins, poly(2-allyl6-methylphenol (AMP: $10 \mathrm{~mol} \%$ )-co-2,6-dimethylphenol (DMP: $90 \mathrm{~mol} \%$ )) (Allyl-PPE), by oxidative coupling copolymerization of DMP with AMP (Scheme 1). ${ }^{7}$ Using large amounts of pyridine, AllylPPEs with narrow molecular weight distributions (MWDs) were obtained, which showed low dielectric losses $\left(\varepsilon^{\prime}=2.4, \tan \delta=0.002\right.$ at $\left.10 \mathrm{GHz}\right)$ than the copolymers with broad MWDs, probably because of the suppression of the branch vibration in the polymers. ${ }^{8}$ Allyl cross-linking reaction, however, required high temperature curing around $260-300{ }^{\circ} \mathrm{C}$, and the $\varepsilon^{\prime}$ and $\tan \delta$ of the resulting polymer were still high.

1,2-Bis(vinylphenyl)ethane (BVPE) is a difunction-

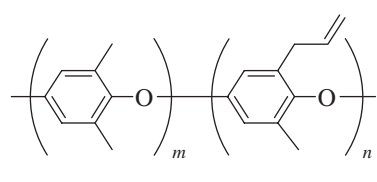

Allyl-PPE

Scheme 1. Chemical structures of poly(2-allyl-6-methylphenol-co-2,6-dimethylphenol) (10 wt \% 2-allyl-6-methylphenole) (Allyl-PPE).

${ }^{\dagger}$ To whom correspondence should be addressed (Tel: +81-3-5734-2128, Fax: +81-3-5734-2128, E-mail: jnunoshige@ polymer.titech.ac.jp). 
al styrenic monomer that can be cured without curing agents at relatively low temperatures, showing a low dielectric loss $\left(\varepsilon^{\prime}=2.5, \tan \delta=0.0012\right.$ at $\left.10 \mathrm{GHz}\right)$ with excellent thermal properties. ${ }^{9}$ Although a low-dielectric loss material consisting of PPE and BVPE has been reported, the molded compounds had a segregated structure, which spoiled the electric and mechanical properties of the resulting material. ${ }^{9} \mathrm{We}$ expected that Allyl-PPE could suppress such a phase separation when molded with BVPE because of copolymerization of Allyl-PPE with BVPE. We here report the synthesis of Allyl-PPE, the dielectric loss and thermal properties, and phase-separated morphologies of the blends with BVPE.

\section{EXPERIMENTAL}

\section{Materials}

DMP was purified by recrystallization from n-hexane. AMP, PPE $\left(M_{\mathrm{n}}=23000, \mathrm{MWD}=2.7\right)$, copper chloride (I) $(\mathrm{CuCl}(\mathrm{I}))$ were purchased from SigmaAldrich Co. Vinylbenzyl chloride $(70 \% \mathrm{~m}$-isomer and $30 \%$ p-isomer) (VBC) was purchased from Tokyo Chemical Industry Co., Ltd. Dehydrated toluene, pyridine and tetrahydrofuran were purchased from Wako Pure Chemical Industries, Ltd. Other solvents and reagents were used as received.

\section{Synthesis of Allyl-PPE}

Allyl-PPE was prepared by the reported method. ${ }^{7}$ A two-necked flask equipped with an oxygen inlet tube and a septum cap was charged with copper (I) chloride $(0.04 \mathrm{~g}, 0.4 \mathrm{mmol})$, magnesium sulfate $(6.0 \mathrm{~g}$, $49.8 \mathrm{mmol})$, dry pyridine $(100 \mathrm{~mL} 1.2 \mathrm{~mol})$, and dry toluene $(100 \mathrm{~mL})$. The mixture was stirred at $25^{\circ} \mathrm{C}$ under a stream of oxygen $(50 \mathrm{~mL} / \mathrm{min})$, yielding a deep-green copper-pyridine complex catalytic solution. To this solution was added a solution of DMP $(3.3 \mathrm{~g}, 27.0 \mathrm{mmol})$ and AMP $(0.45 \mathrm{~mL}, 3.0 \mathrm{mmol})$ in toluene $(50 \mathrm{~mL})$. The mixture was stirred for $90 \mathrm{~min}$ under a stream of oxygen $(50 \mathrm{~mL} / \mathrm{min})$, and then poured into methanol $(1000 \mathrm{~mL})$ containing concentrated $10 \mathrm{M} \mathrm{HCl}(5 \mathrm{~mL})(\mathrm{MeOH} / \mathrm{HCl}$ solution). The precipitate was washed with methanol in several times, dissolved in chloroform, and reprecipitated in $\mathrm{MeOH} / \mathrm{HCl}$ solution. After washing with methanol and drying at $80^{\circ} \mathrm{C}$ for $3 \mathrm{~h}$ and $110^{\circ} \mathrm{C}$ for $6 \mathrm{~h}$ under vacuum, a white fibrous polymer was obtained. (Yield: $3.37 \mathrm{~g}, 91 \%, M_{\mathrm{n}}=24,000, M_{\mathrm{w}} / M_{\mathrm{n}}=2.4$ ).

IR (KBr, v, cm ${ }^{-1}$ ): 1192 (Ar-O-Ar), 914 and 984 $(\mathrm{C}=\mathrm{C}) .{ }^{1} \mathrm{H}$ NMR $\left(\mathrm{CDCl}_{3}, \delta, \mathrm{ppm}\right): 6.47(\mathrm{~s}, 2 \mathrm{H}, \mathrm{Ar})$, $5.84\left(\mathrm{~m}, 0.1 \mathrm{H}, \mathrm{Ar}-\mathrm{CH}_{2}-\mathbf{C H}=\mathrm{CH}_{2}\right), 4.99(\mathrm{~m}, 0.2 \mathrm{H}$, $\left.\mathrm{Ar}-\mathrm{CH}_{2}-\mathrm{CH}=\mathbf{C H}_{2}\right), 3.21\left(\mathrm{~m}, 0.2 \mathrm{H}, \mathrm{Ar}-\mathbf{C H}_{2}-\mathrm{CH}=\right.$ $\left.\mathrm{CH}_{2}\right)$, and $2.09\left(\mathrm{~m}, 5.7 \mathrm{H}, \mathrm{Ar}-\mathbf{C H}_{3}\right) \cdot{ }^{13} \mathrm{C} \mathrm{NMR}\left(\mathrm{CDCl}_{3}\right.$, $\delta, \mathrm{ppm}): 16.77,113.80,114.41,114.74,116.02,132.51$,
$132.78,134.55,136.17,144.88,145.39,154.69$, and 154.91 .

Anal. Calcd. for $\left[\left(\mathrm{C}_{8} \mathrm{H}_{8} \mathrm{O}\right)_{9}\right.$-co- $\left.\left(\mathrm{C}_{10} \mathrm{H}_{10} \mathrm{O}\right)_{1}\right]$ : $\mathrm{C}$, 92.3\%; H, 7.7\%; Found: C, 92.2\%; H, 7.8\%.

\section{Synthesis of BVPE}

BVPE was prepared by the reported method. ${ }^{8} \mathrm{~A}$ $500 \mathrm{~mL}$ three-necked flask equipped with a nitrogen inlet tube, a 100-mL dropping funnel, and a condenser was charged with magnesium turnings $(4.02 \mathrm{~g}, 0.16$ mol) and dry tetrahydrofuran $(300 \mathrm{~mL})$. The mixture was stirred and cooled to $-5^{\circ} \mathrm{C}$. VBC $(45.8 \mathrm{~g}, 0.30$ mol) was added slowly into the mixture and the reaction system was stirred at $0{ }^{\circ} \mathrm{C}$ for $20 \mathrm{~h}$. The reaction mixture was filtered and the solvent was evaporated. The residue was dissolved in $200 \mathrm{~mL}$ of hexane. The hexane solution was then washed with aqueous $1 \mathrm{M}$ $\mathrm{HCl}$ once and with water twice, using a separatory funnel. The solution was dried over $\mathrm{MgSO}_{4}$ and the solvent was evaporated. The product was dissolved in hexane and the solution was passed through a short column packed with silica gel. The purified product was obtained by removal of the solvent. BVPE was a mixture of $p, p$-isomer, $m, m$-isomer, and $m, p$-isomer. (Yield: $31.8 \mathrm{~g}, 91 \%$ ).

IR $\left(\mathrm{KBr}, v, \mathrm{~cm}^{-1}\right)$ : 906 and $991(\mathrm{C}=\mathrm{C}) .{ }^{1} \mathrm{H}$ NMR $\left(\mathrm{CDCl}_{3}, \delta, \mathrm{ppm}\right): 7.00-7.35$ (8H, multiplet, $\mathrm{Ar}$ ), 6.69 $\left(2 \mathrm{H}, \mathrm{Ar}-\mathbf{C H}=\mathrm{CH}_{2}\right), 5.71,5.21\left(2 \mathrm{H}, \mathrm{Ar}-\mathrm{CH}=\mathbf{C H}_{2}\right)$, $2.90\left(4 \mathrm{H}, \mathrm{Ar}-\mathbf{C H}_{2}-\mathbf{C H}_{2}-\mathrm{Ar}\right) .{ }^{13} \mathrm{C} \mathrm{NMR}\left(\mathrm{CDCl}_{3}, \delta\right.$, ppm): 141.90, 141.86, 137.59, 137.57, 136.90, 136.63, $135.35,128.60,128.50,127.98,126.36,126.19,123.89$, $123.88,113.66,113.00,37.75,37.56$ and 37.49 .

Anal. Calcd. for $\mathrm{C}_{18} \mathrm{H}_{18}$ : C, 92.3\%; $\mathrm{H}, 7.7 \%$. Found: C, 92.1\%; H, 7.8\%.

\section{Molding of Polymer and Polymer Blends}

The polymer blends (BVPE and PPE, BVPE and Allyl-PPE) were molded by the following procedure. PPE or Allyl-PPE and BVPE were dissolved in chloroform. The mixture was dried on a PTFE film at room temperature, and at $90^{\circ} \mathrm{C}$ for $30 \mathrm{~min}$. The dried mixture was molded by multistage heating $\left(120^{\circ} \mathrm{C}\right.$ for $30 \mathrm{~min}, 150^{\circ} \mathrm{C}$ for $30 \mathrm{~min}$, and $230^{\circ} \mathrm{C}$ for $60 \mathrm{~min}$ ) under pressing (1 MPa) in a vacuum condition. Homogeneous PPE and Allyl-PPE resin were molded by single step heating $\left(230^{\circ} \mathrm{C}\right.$ for $\left.60 \mathrm{~min}\right)$ under pressing (1 MPa) in a vacuum condition. BVPE resin was molded in spacers with multistage heating $\left(120^{\circ} \mathrm{C}\right.$ for $30 \mathrm{~min}, 150^{\circ} \mathrm{C}$ for $30 \mathrm{~min}$ and $230^{\circ} \mathrm{C}$ for $60 \mathrm{~min}$ ) under nitrogen atmosphere without pressure. All samples were cooled down with water jacket in the vacuum press. The thickness of these molded films was about $1.0 \mathrm{~mm}$. To measure the tensile strength and the dynamic mechanical properties, the sample was cut out to the width of $5 \mathrm{~mm}$. To measure the di- 
electric loss, the sample was cut out to the width of $1.5 \mathrm{~mm}$.

\section{IR Measurement}

Samples for IR measurement were prepared by the following procedure. Allyl-PPE and the polymer blends were dissolved in toluene $(20 \mathrm{wt} \%)$. The solution was cast on a Si wafer $(1000 \mathrm{rpm}, 30 \mathrm{sec})$ and heated under nitrogen $\left(210-260^{\circ} \mathrm{C}\right.$ for $\left.60 \mathrm{~min}\right)$. BVPE was heated on a slide glass under nitrogen (120$260{ }^{\circ} \mathrm{C}$ for $60 \mathrm{~min}$ ). Pulverized fragment of Cured BVPE was mixed with $\mathrm{KBr}$ tablet.

\section{Energy-filtering Transmission Electron Microscopy (EFTEM)}

An LEO922 in-column-type energy-filtering transmission electron microscope with a LaB6 cathode equipped with an Omega-type energy spectrometer was used at an accelerating voltage of $200 \mathrm{keV}$. To obtain high-resolution elemental maps and to perform quantitative chemical analysis, we employed the Image-EELS technique. The detailed instrumental setup and the scheme of the process were described in the previous papers. ${ }^{10-13}$

\section{Measurements}

Infrared spectra were recorded on a Horiba FT-720 spectrophotometer. ${ }^{1} \mathrm{H}$ and ${ }^{13} \mathrm{C}$ NMR spectra were recorded using a BRUKER DPX300 $(300 \mathrm{MHz})$ spectrometer. Thermogravimetry (TG) and dynamic mechanical analysis (DMA, $0.02 \mathrm{~Hz}$ ) were performed with a Seiko TG/DTA 6300, TMA/SS 6100, heating rate of $5{ }^{\circ} \mathrm{C} / \mathrm{min}$ under nitrogen, respectively. Number- and weight-average molecular weights $\left(M_{\mathrm{n}}\right.$ and $M_{\mathrm{w}}$ ) were determined by a gel permeation chromatograph (GPC) on a Jasco GULLIVER 1500 system equipped with a polystyrene gel column (Plgel $5 \mathrm{~mm}$ MIXED-C) eluted with chloroform at $40^{\circ} \mathrm{C}$ at a flow rate of $1.0 \mathrm{~mL} / \mathrm{min}$ calibrated by standard polystyrene samples. Tensile strength and elongation were measured with a Shimadzu autograph AGS-100G. The dielectric constants $\left(\varepsilon^{\prime}\right)$ and the dielectric loss tangent $(\tan \delta)$ were measured with an Agilent Technology type 810 network analyzer connecting cavity resonators of Kanto Densi Ouyou at room temperature.

\section{RESULTS AND DISCUSSION}

\section{Thermosetting Reaction of Allyl PPE with BVPE}

Allyl-hydrogen abstraction occurs thermally, and the produced allyl radical is capable of abstracting hydrogen from hydrocarbons and of adding to olefinic double bonds; thus, Allyl-PPE possesses thermosetting property. However, the high curing temperature was needed for the thermosetting reaction, mainly be-

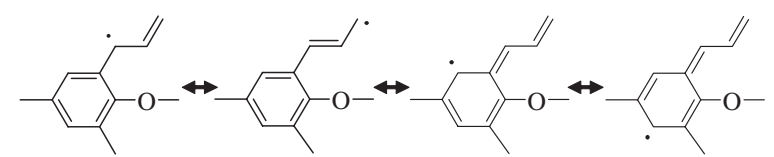

Scheme 2. Resonance structures of intermolecular allyl radical.

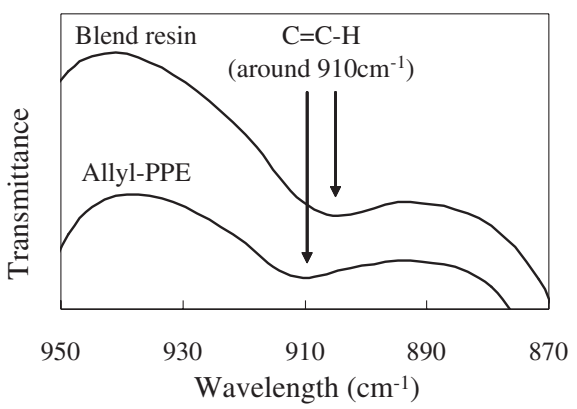

(a)

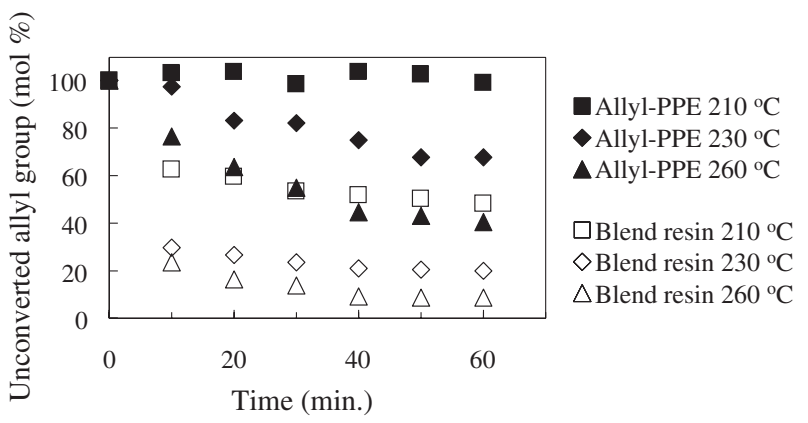

(b)

Figure 1. (a) IR spectrum of Allyl-PPE alone and that blended with BVPE (50 wt \%) (Monitored by the absorption at 910 $\mathrm{cm}^{-1}$ corresponding to the $\mathrm{C}=\mathrm{C}$ stretching). (b) Change of crosslinking reaction with time (Allyl-PPE and that blend with BVPE $(50 \mathrm{wt} \%)$ ). The decrease of vinyl group's absorption came from Allyl-PPE and BVPE (around $910 \mathrm{~cm}^{-1}$ ) and the absorption was corrected by other absorption $\left(1191 \mathrm{~cm}^{-1}\right.$ (Ar-O-Ar)).

cause of the resonance stabilization of phenylallyl radicals (Scheme 2). To lower the curing temperature, Allyl-PPE was blended with BVPE as a cure promoter. AllyPPE was prepared according to the reported procedure. ${ }^{8}$ The progress of thermosetting reaction of Allyl-PPE alone and that blended with BVPE $(50 \mathrm{wt} \%)$ were monitored by the decrease of the absorption at $910 \mathrm{~cm}^{-1}$ corresponding to the $\mathrm{C}=\mathrm{C}$ stretching in the IR spectrum as shown in Figure 1a, and the temperature dependence of cross-linking reaction is shown in Figure 1b. The cross-linking of AllylPPE does not proceed at $210^{\circ} \mathrm{C}$, and the consumption of vinyl groups was less than $60 \%$ even at $260^{\circ} \mathrm{C}$ for $1 \mathrm{~h}$ curing. Meanwhile, because of the high reactivity of styryl group, the absorption rapidly decreases when $50 \mathrm{wt} \%$ of BVPE is added to Allyl-PPE. The vinyl groups of $95 \%$ is consumed for $1 \mathrm{~h}$ in the blended res- 


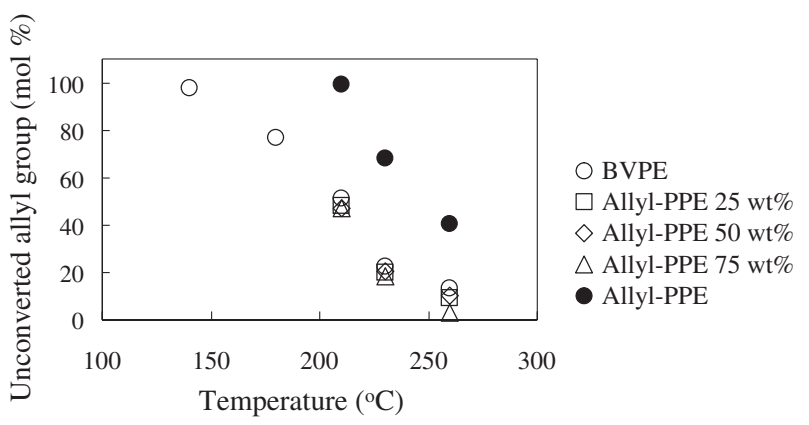

Figure 2. Temperature dependence of crosslinking reaction (molded for $60 \mathrm{~min}$ ). The decrease of vinyl group's absorption came from allyl group (Allyl-PPE) and styryl group (BVPE) (around $910 \mathrm{~cm}^{-1}$ ). The absorption was corrected by other absorption (Allyl-PPE and blend resins: $1191 \mathrm{~cm}^{-1}$ (Ar-O-Ar), BVPE: $713 \mathrm{~cm}^{-1}$ (Ar)).

in cured at $260^{\circ} \mathrm{C}$, indicating BVPE effectively functions as a cure promoter.

Figure 2 shows the dependence of the thermosetting reaction of blended resins with various compositions on the curing temperature. While the reaction in Allyl-PPE alone is slow, those in all the blended resins quickly proceed. Johansson et al. reported that no chain transfer reaction was observed for the free-radical polymerization of styrene in the presence of allyl ethers, ${ }^{14}$ from which we could expect that BVPE should be polymerized independently on the amounts of Allyl-PPE. Contrary to what is expected, almost complete consumption of vinyl groups is observed for the blended resin composed of $22 \mathrm{~mol} \%$ of allyl groups with $78 \mathrm{~mol} \%$ of styryl groups (Allyl-PPE blended with $\operatorname{BVPE}(25 \mathrm{wt} \%)$ ), and the more vinyl groups is remained in the blended resins with less amounts of Allyl-PPE. These results indicate that Allyl group in Allyl-PPE is consumed during the curing with BVPE, and the thermosetting reaction proceeds more effectively with larger amounts of AllylPPE, which could act as a diluting agent for the thermosetting of BVPE. Moreover, the molded Allyl-PPE films containing BVPE are insoluble in any organic solvents such as chloroform and heated toluene. The higher vinyl conversion results in higher thermal stability of the resins as shown in Figure 3.

The mechanical properties of the polymer films were first investigated by dynamic mechanical analysis. Figure 4 depicts the dependence of the storage modulus $\left(E^{\prime}\right)$ and the storage loss tangent $(\tan \delta)$ on the temperature. All samples show softening temperature at $210^{\circ} \mathrm{C}$, corresponding to the glass transition of PPE backbone, which indicates the existence of PPE and cured BVPE domains. The $E^{\prime}$ of Allyl-PPE homopolymer rapidly decreases just after the $T_{\mathrm{g}}$, but AllylPPE resins blended with BVPE maintains the $E^{\prime}$ value even above $210^{\circ} \mathrm{C}$. These results clearly indicate that

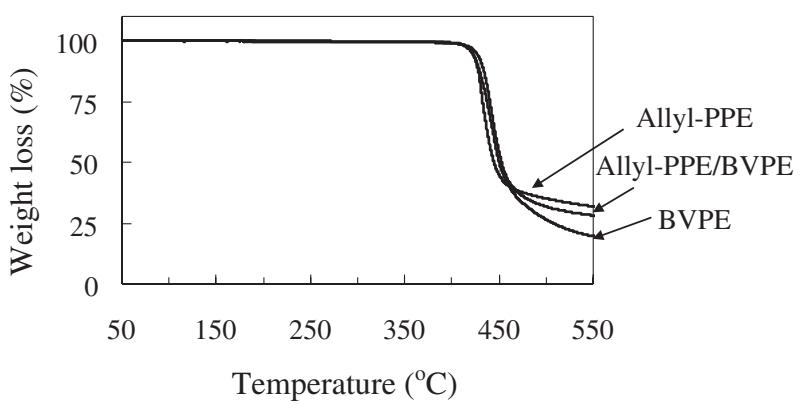

Figure 3. TGA trace for molded Allyl-PPE/BVPE (AllylPPE: $50 \mathrm{wt} \%$ ), Allyl-PPE and BVPE.

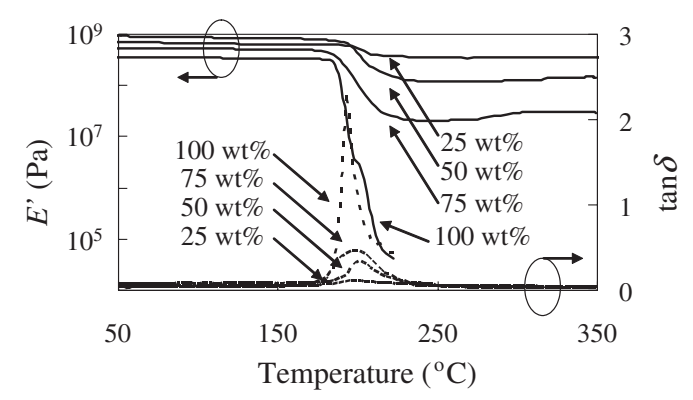

Figure 4. Dynamic mechanical analysis measurement of molded Allyl-PPE/BVPE (Allyl-PPE: wt \%).

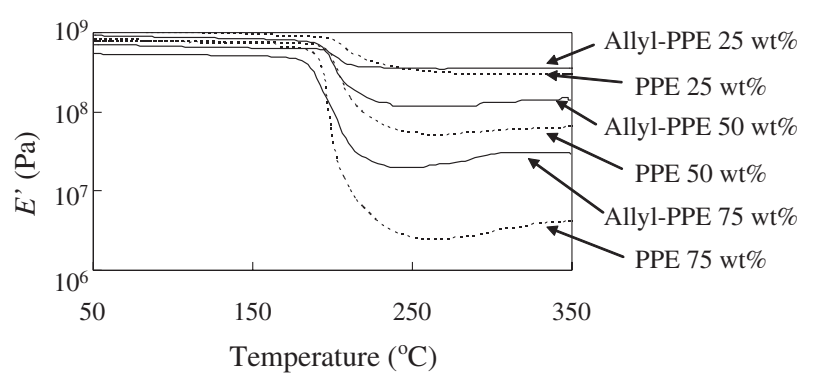

Figure 5. The dynamic mechanical properties of Allyl-PPE/ BVPE and PPE/BVPE. (measured by TMA/SS).

Allyl-PPE resins are reinforced by the addition of BVPE.

The dynamic mechanical properties of Allyl-PPEand PPE-based resins are shown in Figure 5. In any composition, Allyl-PPE-based resin shows better mechanical properties than PPE-based one. Allyl group gives better miscibility to BVPE resin, which might be caused by the chemical or physical binding between these two resins. Consequently, the segregated domain size in Allyl-PPE resin blended with BVPE could be much smaller than that in the PPE with BVPE because the final $E^{\prime}$ of the former resin was higher than that of the latter one.

\section{Mechanical Properties of the Molded Resin}

Cured BVPE has low mechanical properties and is comparatively fragile. However, BVPE has good 


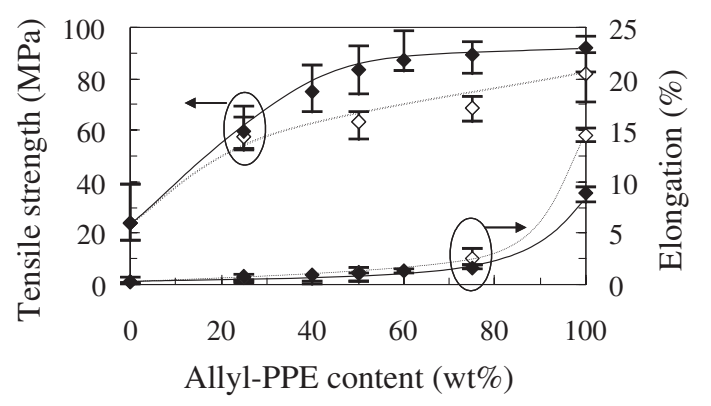

$\diamond \mathrm{PPE} / \mathrm{BVPE}$

$\diamond$ Allyl-PPE/BVPE

Figure 6. Tensile strength and elongation measurements of molded PPE/BVPE and Allyl-PPE/BVPE.

compatibility with PPE resin, so the mechanical properties would be improved by blending with PPE. Further mechanical properties of the films are collected with a tensile instrument as shown in Figure 6. Increasing the amounts of BVPE, the elongation and the tensile strength of the films based on PPE with BVPE are decreased. On the other hands, the tensile strength of Allyl-PPE film containing BVPE below $50 \mathrm{wt} \%$ maintains more than $95 \%$ of the original strength. This indicates that the two polymers are well miscible each other to form the segregated domains whose size is much smaller than that in PPE with BVPE.

\section{Characterization of the Phase-Separated Morpholo- gies}

The blends of PPE/BVPE and Allyl-PPE/BVPE are transparent even after the curing, which suggests the high compatibility or the comparable refractive indices between the components. The phase-separated morphologies of the blends could not be observed by conventional transmission electron microscopy (TEM). However, the oxygen distribution images created by EFTEM clearly reveal the phase separation of the blends, which can be characterized as oxygen-rich and -poor regions. Moreover, the compositional differences in the two phases can be estimated from the integrated intensities of oxygen ionization edges (O K-edges) by EELS acquired from the two regions. The detailed process for acquiring the elemental maps and for estimating the elemental ratios between the two phases by EELS have been shown in our previous papers. ${ }^{10-13}$ Table I summarizes the oxygen distribution images and the ratios of the oxygen concentrations of the two blend series obtained by EFTEM. Clear large domains are observed in the films containing PPE and BVPE, where the size of the domains is in the range of 100 to $300 \mathrm{~nm}$. On the other hand, no segregations are observed in Allyl-PPE containing blends when AllylPPE content is higher than $50 \mathrm{wt} \%$. And, it was difficult to confirm not only the phase-separated structures but also the differences of the oxygen concentrations. This result indicates a very small phase separation $(<10 \mathrm{~nm})$ existed in the blend resin along with the result of the glass transition temperature measured by DMA. The differences in the mechanical properties of the samples seem to be attributed to the appearance of the phase-separated structures. The mechanical properties of the blend resin were improved by the good miscibility and the thermosetting reaction.

Table I. Oxygen maps of molded Allyl-PPE/BVPE and PPE/BVPE, and elemental ratio (O-rich/O-poor)

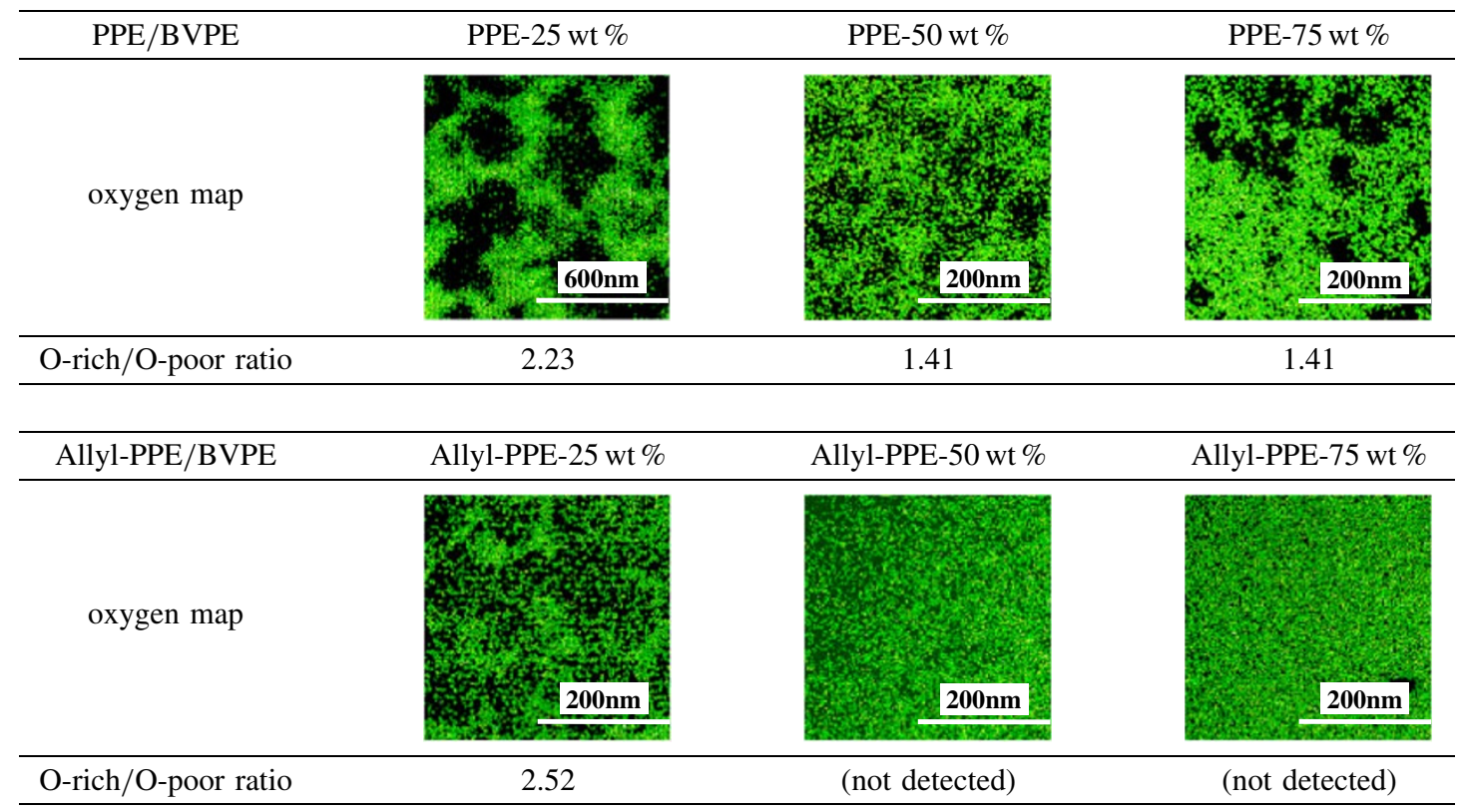




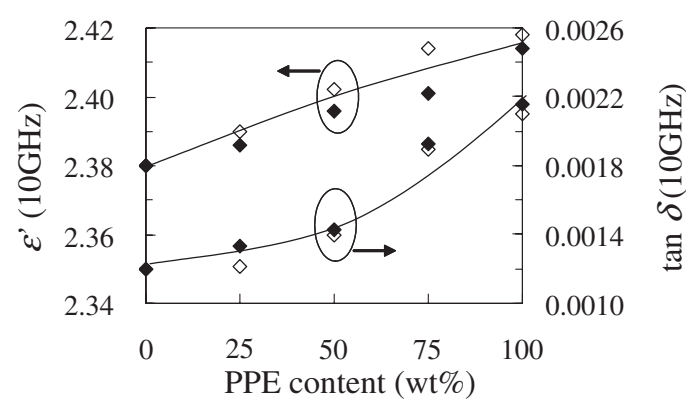

$\triangle \mathrm{PPE} / \mathrm{BVPE}$

Allyl-PPE/BVPE

Figure 7. Dielectric properties of molded Allyl-PPE/ BVPE and PPE/BVPE.

Table II. Properties of molded Allyl-PPE/BVPE and PPE/BVPE

\begin{tabular}{cccccc}
\hline BVPE & 100 & 75 & 50 & 25 & 0 \\
Allyl-PPE & 0 & 25 & 50 & 75 & 100 \\
\hline$\varepsilon^{\prime}(10 \mathrm{GHz})$ & 2.38 & 2.39 & 2.40 & 2.40 & 2.41 \\
$\tan \delta(10 \mathrm{GHz})$ & 0.0012 & 0.0013 & 0.0014 & 0.0019 & 0.0022 \\
Tensile strength $(\mathrm{MPa})$ & 23.7 & 59.3 & 83.4 & 89.2 & 91.8 \\
Elongation $(\%)$ & 0.3 & 0.8 & 1.1 & 1.6 & 8.9 \\
$T_{\mathrm{g}}\left(\mathrm{TMA} / \mathrm{SS},{ }^{\circ} \mathrm{C}\right)$ & $>400$ & 200 & 201 & 196 & 193 \\
$T_{\mathrm{d} 10}\left(\mathrm{TGA},{ }^{\circ} \mathrm{C}\right)$ & 428 & 432 & 433 & 430 & 427 \\
\hline
\end{tabular}

\section{Electric Properties of the Molded Resin}

Dielectric constant and the dielectric loss at $10 \mathrm{GHz}$ were measured as the electric properties of Allyl-PPE based samples in Figure 7. These two parameters decrease with increasing the amounts of BVPE because of a lack of heteroatom and of the high cross-linking density, which suppress the vibration of the molecules.

Table II summarized the properties of Allyl-PPE blended with and without BVPE. Cured BVPE possesses poor mechanical strength and toughness, but these properties are improved by blending with Allyl-PPE resin. The blended resins show lower dielectric constant and dielectric loss tangent with excellent thermal stability compared with the other high temperature dielectric loss materials, thus, the blended resin is a good candidate for the next generation insulating material.

\section{CONCLUSIONS}

Poly(2-allyl-6-methylphenol-co-2,6-dimethylphenol) (Allyl-PPE) blended with 1,2-bis(vinylphenyl)ethane (BVPE) were molded, and their cross-linking reactions, thermal properties, mechanical properties, phase separations and electric properties were studied. By blending with BVPE, the cross-linking reaction of allyl group in Allyl-PPE efficiently proceeded. The resulting polymer blend showed better thermo-mechanical properties, indicating the better miscibility of the components. The small domain size less than $10 \mathrm{~nm}$ was observed by EELS technique. The dielectric constant and dielectric loss were varied by changing the components ratio of Allyl-PPE and BVPE.

Acknowledgment. This work was supported by the New Energy and Industrial Technology Development Organization (NEDO) through a grant for the Nanostructured Polymeric Materials Project under the Nanotechnology Program, Japan (2001-2008).

\section{REFERENCES}

1. G. Maier, Prog. Polym. Sci, , 26, 3 (2001).

2. H. N. Hendricks, Solid State Technol., 5, 117 (1995).

3. R. N. Vrtis, K. A. Heap, W. F. Burgoyne, and L. M. Robeson, Mater. Res. Soc. Symp. Proc., 443, 171 (1997).

4. Y. Watanabe, Y. Shibasaki, S. Ando, and M. Ueda, Polym. J., 38, 79 (2006).

5. K. Tsuchiya and M. Ueda, Polym. J., 38, 956 (2006).

6. A. S. Hay, J. Polym. Sci., 58, 581 (1962).

7. T. Fukuhara, Y. Shibasaki, S. Ando, and M. Ueda, Polymer, 45, 843 (2004).

8. J. Nunoshige, H. Akahoshi, Y. Shibasaki, and M. Ueda, Chem. Lett., 36, 2, 238 (2007).

9. S. Amou, S. Yamada, A. Takahashi, A. Nagai, and M. Tomoi, J. Appl. Polym. Sci., 92, 1252 (2004).

10. S. Horiuchi, T. Hamanaka, T. Aoki, T. Miyakawa, R. Narita, and H. Wakabayashi, J. Electron Microsc., 52, 3, 255 (2003).

11. S. Horiuchi, D. Yin, and T. Ougizawa, Macromol. Chem. Phys., 206, 7 (2005).

12. S. Horiuchi and H. Dohi, Langmuir, 22, 4607 (2006).

13. Y. Liao, S. Horiuchi, J. Nunoshige, H. Akahoshi, and M. Ueda, Polymer, 48, 3749 (2007).

14. M. Johansson and A. Hult, J. Polym. Sci. Part A: Polym. Chem., 29, 1, 9 (2003). 